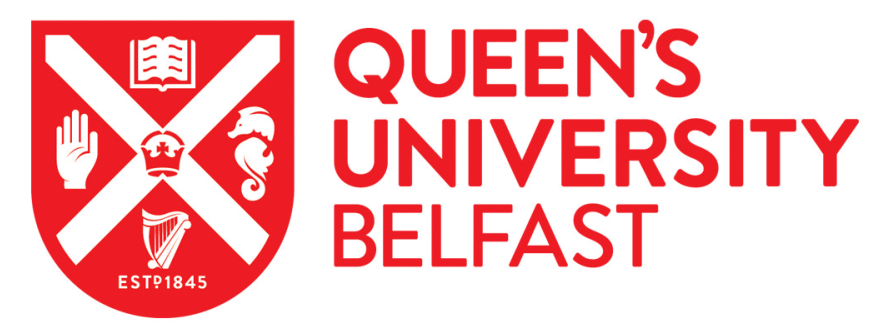

\title{
Applying the recovery approach to the interface between mental health and child protection services
}

Duffy, J., Davidson, G., \& Kavanagh, D. (2016). Applying the recovery approach to the interface between mental health and child protection services. Child Care in Practice, 22(1), 35-49.

https://doi.org/10.1080/13575279.2015.1064358

\section{Published in:}

Child Care in Practice

\section{Document Version:}

Peer reviewed version

Queen's University Belfast - Research Portal:

Link to publication record in Queen's University Belfast Research Portal

\section{Publisher rights}

(C) 2015 Taylor \& Francis Group,

This is an Accepted Manuscript of an article published by Taylor \& Francis in Child Care in Practice on 7th September 2014, available online: http://wwww.tandfonline.com/10.1080/13575279.2015.1064358.

\section{General rights}

Copyright for the publications made accessible via the Queen's University Belfast Research Portal is retained by the author(s) and / or other copyright owners and it is a condition of accessing these publications that users recognise and abide by the legal requirements associated with these rights.

Take down policy

The Research Portal is Queen's institutional repository that provides access to Queen's research output. Every effort has been made to ensure that content in the Research Portal does not infringe any person's rights, or applicable UK laws. If you discover content in the Research Portal that you believe breaches copyright or violates any law, please contact openaccess@qub.ac.uk. 
Title: Applying the recovery approach to the interface between mental health and child protection services

Authors: Joe Duffy, Lecturer in Social Work, School of Sociology, Social Policy and Social Work, Queen's University Belfast

Gavin Davidson, Lecturer in Social Work, School of Sociology, Social Policy and Social Work, Queen's University Belfast

Damien Kavanagh, Mental Health Recovery Social Worker, Belfast HSC Trust

Corresponding author: Joe Duffy, Lecturer in Social Work, School of Sociology, Social Policy and Social Work, Queen's University Belfast, Belfast, Northern Ireland, BT7 1NN. Email: joe.duffy@qub.ac.uk 
Title: Applying the recovery approach to the interface between mental health and child protection services

\begin{abstract}
There are a range of theoretical approaches which may inform the interface between child protection and adult mental health services. These theoretical perspectives tend to be focused on either child protection or mental health with no agreed integrating framework. The interface continues to be identified, in research, case management reviews and inquiry reports, as complex and problematic. This paper proposes that more positive, integrated approaches to service user engagement, risk assessment and management may lead to better outcomes in working with families experiencing parental mental health problems and child protection concerns. It is proposed that the recovery approach, increasingly used in mental health services, can inform the processes of engagement, assessment and intervention at the mental health and child protection interface. The article provides a critical overview of the recovery approach and compares it with approaches typifying interventions in child protection work to date. Relevant research and inquiries are also examined as a context for how to more effectively respond to cases where there are issues around parental mental health problems and child protection. The article concludes with case material to illustrate the potential application of the recovery approach to the interface between mental health and child protection services.
\end{abstract}

Key words: recovery approach, child protection, mental health, interface working 


\section{Introduction}

The evidence documenting the relationship between parental mental health problems and child protection is well established (Rutter and Quinton, 1984; Falkov, 1996; Sinclair and Bullock, 2002; Kearney, Levin \& Rosen. 2003; Tunnard, 2004; Stallard, Norman, Huline-Dickens, Salter \& Cribb, . 2004; Brandon, 2009; Cleaver, Unell \& Aldgate, . 2011). The seminal publication Child Protection: Messages from Research (Department of Health, 1995) highlighted the co-existence of parental mental illness in many families where there were child protection concerns. Falkov's work (1996), examining those cases where children had been killed, concluded that parental mental illness was a factor in one third of these families. Reder and Duncan's research (1999) also indicated the prevalence of parental mental illness in 43 per cent of the cases they examined where children had died. Considerable numbers of children and families therefore have contact with both child protection and mental health systems. Nonetheless, interdisciplinary working across this interface has been problematic $($ Falkov, 1996) with repeated calls for professionals to develop better ways to work together in helping families experiencing mental health and child protection problems (Sinclair and Bullock, 2002; Social Care Institute of Excellence (SCIE), 2009; Rouf, Larkin \& Lowe, 2011).

This paper proposes that the recovery approach may offer an alternative to workers involved in this interface at a time when existing responses tend to be both risk avoidant and overly managerial (Munro, 2010). The recovery approach, most commonly associated with mental health, is not new. It builds on established strengths (Saleeby, 2006; Walsh and Canavan, 2014), resilience (Rutter, 2007) and person-centred (Wilson, Ruch, Lymbery \& Cooper. 2009; Ruch, Turney \& Ward. 2010) ways of working aimed at empowering service users to have an active role in 
effecting change in their lives. Central to this approach is the need to work with service users in a way which promotes openness, trust, resilience and partnership in the quest to address problems. The recovery approach, with its emphasis on openness, trust and hope, fits within established strengths and resilience based ways of working with service users. Supporting the view of "resilience as the capacity that individuals.....have to resist the negative aspects of harm and experience and still develop a positive and generative aspect" (Hothersal and Maas-Lowitt, 2010, p. 105), Author (2012, p. 159) also argues that "the resilience and strengths often demonstrated by parents and children should be acknowledged and supported" when working at the interface.

\section{The recovery approach}

Over the past thirty years the recovery approach has become increasingly influential in mental health services. It developed from a range of influences including: deinstitutionalisation; therapeutic communities; civil rights; and more personal accounts of people living with mental health problems (Fardella, 2008; Roberts, Davenport, Holloway \& Tattan. 2006). There are a range of meanings for the term 'recovery' and its definition has been the focus for some debate (Shepherd, Boardman \& Slade. 2008). It has been discussed as an approach, a model, a process, a vision and a set of principles, and there is no agreed definition (Office of the Surgeon General, 1999).In the mental health field, the general meaning tends to involve a focus on people finding ways to develop and follow their own goals in the context of on-going mental health problems (Roberts and Wolfson, 2006). The most commonly used definition is by Anthony (1993, p. 527) who describes recovery as: "A deeply personal, unique process of changing one's attitudes, values, feelings, 
goals, skills, and/or roles. It is a way of living a satisfying, hopeful, and contributing life even with limitations caused by illness". Davidson (2003, p.45), suggests recovery involves incorporating mental health problems as a part, but only one aspect, of identity. The recovery approach is therefore not focused on the conventional sense of getting better, a complete absence of symptoms or 'clinical recovery', which may not be possible for many people, but on a positive approach to 'personal recovery' which involves getting on with what you want to do even with ongoing mental health problems (Slade, 2009).

The Scottish Recovery Network (2008) has identified the key elements of the approach as: hope; meaning and purpose; control and choice; self-management techniques; positive risk-taking; relationships; and social inclusion. So the approach emphasizes: the internal attitudes, beliefs and processes of the person; the external circumstances they are living in; and how these internal and external conditions interact (Jacobson and Greenley, 2001). This way of thinking about and responding to mental health problems supports and can perhaps further develop positive and systemic approaches to working with parents with mental health problems.

An initial criticism of this approach is that using the term 'recovery' can be misleading. Confusion between 'clinical recovery' and the 'recovery approach' may lead to clients and carers having unrealistic expectations of what is possible for them or may involve practitioners colluding with a denial of illness (Care Services Improvement Partnership, Royal College of Psychiatrists and Social Care Institute of Excellence.2007). It has also been suggested that 'recovery' is a 'polyvalent concept', in other words can be defined in many different ways and for many 
different purposes (Pilgrim, 2008). These concerns though do appear to be mainly about differences in definition and/or concerns about how the approach may be applied rather than the approach itself. Notwithstanding such concerns, it is important to explore the potential for this approach to deliver a more effective response to families.

\section{Policy context of the recovery approach}

The recovery approach first appeared in mental health policy in New Zealand (Mental Health Commission, 1998), the US (Department of Health and Human Services, 2003), Australia (Australian Government, 2003) and then Ireland (Mental Health Commission, 2005). In the UK, its acceptance by policy makers is becoming increasingly clear, for example, the Scottish Executive $(2007$, p. 1) has developed a measure, the Scottish Recovery Indicator, to "assess the degree to which organisations and programmes meet our expectations in respect of equality, social inclusion, recovery and rights". In England, a key theme of New Horizons, the Department of Health's (2009, p.3) vision for mental health services over the next ten years, is "personalised care - ensuring that care is based on individuals' needs and wishes, leading to recovery". There is a concern about the extent to which these policy developments have translated into practice and it is possible that, even when the recovery approach is the central policy ethos, traditional deficit focused approaches could persist in practice (Harper and Speed, 2012).

\section{Implications of the recovery approach for mental health practice}

The recovery approach has major implications for practice. Schrank and Slade (2007, p.324) argue that adopting this approach involves redefining the goals of 
mental health services to prioritise the person's own goals rather than focusing almost exclusively on their illness. Borg and Kristiansen (2004, p. 504) have attempted to identify what recovery-oriented practice involves and state that "a central and greatly valued support from the professionals was finding ways to convey optimism, encouraging the person's belief in him/herself, and in general, keeping hope alive". They also suggest that practice based on the recovery approach is characterized by: "openness, collaboration as equals, a focus on the client's strengths and resources, reciprocity; and willingness 'to go the extra mile"' (Shepherd et al. 2008). One of the main implications for practice therefore involves a move away from the expert practitioner towards the acceptance that engagement with the client in this process and partnership working are central (Department of Health, 2009).

Slade (2009) identifies a range of ways in which professionals may support recovery. These include: focusing on the priorities of the service user; facilitating access to information and peer support; helping develop confidence and self-esteem; using assessment and person-centred planning to amplify strengths, foster personal responsibility and encourage self-management. There are also very specific interventions within the recovery approach such as the Wellness Recovery Action Plan (WRAP) which is a "manualized group intervention for adults with mental illness. WRAP guides participants through the process of identifying and understanding their personal wellness resources ("wellness tools") and then helps them develop an individualized plan to use these resources on a daily basis to manage their mental illness" (National Registry of Evidence-based Programs and Practices, 2010). The recovery approach isn't intended to replace the wide range of 
evidence based interventions already developed to respond to mental health problems but rather it can provide a more positive framework within which these interventions can be provided (Rosen and O'Halloran, 2014).

The recovery approach, rooted in principles of openness, choice, partnership, hope and respect may represent an important vehicle for effectively working with reluctant and involuntary service users. Research in both child protection and mental health point to better practice outcomes when social workers convey openness (Laurence, 2003). Trotter (2006) refers to the findings from Child Protection - Messages from Research which highlighted that "effective work in child protection is characterised by honesty on the part of the worker and clarity about what is happening and the options available" (p.22). Sherman's (1988) meta-analysis of social work effectiveness in mental health also concluded that "mental health clients had better outcomes if the intervention and the client's role are described clearly and discussed with the client..." (cited in Trotter, 2006:22). Furthermore, optimism in general is regarded as being a positive attribute for social workers to convey both in mental health social work (Ryan et al. 2004) and linked to achieving better outcomes in child protection social work (Trotter, 2004). The recovery approach suggests that "services need to move beyond the current preoccupations with risk avoidance...towards working with constructive and creative risk-taking and what is personally meaningful to the individual and their family" (CSIP et al. 2007, p.6). Courtney and Moulding (2014) have acknowledged that approaches to promote recovery and manage risk, including through compulsory intervention, may initially appear to be contradictory. In their qualitative study of social workers however they found that not only is it possible to manage the potential tensions between recovery 
and risk these aspects of practice can be complementary. In practice this means that risk must still be fully assessed and managed, but how this is achieved may focus more on involving the service user and other key people to highlight needs, strengths and opportunities for positive change (Boardman and Roberts, 2014).

\section{Why is the Interface important?}

The interface between mental health and child protection services involves a plethora of considerations and is much more than a narrow focus on communication between mental health and child protection social work staff (Author, 2012). Issues around working systems, structures, cultures and priorities also have to be carefully factored in. In both mental health and child protection services there will usually also be a range of different professionals involved and a number of different agencies, such as education, advocacy, the police, probation, voluntary sector and other health and social care agencies (Tye and Precey, 1999). Referring to the interface, therefore, encompasses not only the direct exchanges between mental health and child protection but how all of the people involved engage with the service users to ensure the best possible outcomes.

Mental illness affects one in five members of the adult population, of which $30-50$ per cent are parents (Rouf et al. 2011). The presence of mental illness does not however militate against healthy parenting (Evans and Fowler, 2008). It is argued instead that the impact of mental illness on parenting can range from non-existent to severe (Rouf et al. 2011:174). At the more severe end, research confirms that children in some instances can experience a range of adverse parenting (Cleaver et al. 2010) with the situation becoming compounded when parents also have problems with substance misuse and domestic violence (Brandon, 2009). Reporting on cases 
involving fatal child abuse, Reder and Duncan (1999) found a significant association between child deaths and caregiver mental ill health. Looking at 'confirmed' cases in particular, where abuse was the primary cause of these child fatalities, in $43 \%$ of such cases the parents had an on-going mental health problem. They also cite evidence to show that "child-maltreating parents are often shown to be depressed or to have a history of attempted suicide" (p. 45) and cite an English study where, in $31 \%$ of cases where children's names were on the Child Protection Register, there was evidence of parental mental illness (see Glaser and Prior 1997). Cleaver et al. (2011) however contest, in the light of serious case review findings undertaken by Brandon et al. (2009) and Brandon et al. (2010) that the figures are considerably higher.

\section{What are the challenges for addressing the interface?}

The need for careful and comprehensive assessment is of central importance to such interface work. Nonetheless, Reder and Duncan $(1999$, p. 56) used the term 'assessment paralysis' to describe the challenges they felt often typified social workers experiences in these situations with disproportionately more priority being given to the psychiatric issues than to the child protection dimensions. Consequently, these authors recommend an emphasis on the behaviour of parents as opposed to their psychiatric diagnosis and symptoms. Such a refocused response would necessarily involve examining the interaction of parents' thoughts, feelings and behaviour. In such a context, Reder and Duncan (1999) called for mental health professionals to 'think family' when approaching the dual concerns of mental health problems and child protection. Such a systems based refocusing however requires a relationship based approach to practice which of itself can present challenges to 
social workers engaged in the child protection/mental health interface.

Research by Stanley, Penhale, Riordan, Barbour \& Holden (2003) locates difficulties at this relational level and reported that child protection social workers struggled to get the time in their work for "active listening" ( $p, 212)$, whereas this was an area where mental health social workers were judged better by service users.

The nuances presented by particular mental health conditions may present significant challenges for social workers protecting children. Martins and Gaffan (2000) suggest that parents with mental health issues may struggle to engage with their children and professionals when they are contending with their own emotions. This view is supported by Cleaver et al. (2011, p.69) in their findings about how particular mental health difficulties caused by depression and schizophrenia negatively impacted on parents' emotional responses to their children. This point is also linked to the challenges which professionals face in working with service users who may be resistant to and deeply suspicious of services, especially social work. Relationship-based and partnership work in both mental health and child protection is therefore challenging. Beresford (2005) uses the term service refusers to more accurately typify mental health service users' poor perception towards mental health service providers. In regard to working with such service users who are reluctant to engage, McLaughlin (2009) points out the stark reality that social workers ultimately are tasked with professional judgement within their legal, procedural and policy mandates which may run contrary to service users' views and wishes. Ferguson (2005, p. 794) however offers a more balanced position and calls for social workers to exercise negotiation skills when dealing with cases which are inherently messy, destructive and challenging. This will involve getting what he refers to as the mundane minutiae of practice right in a quest to support both children and adults 
who are vulnerable. In this territory, Ferguson (2005, p. 793) states that social workers need to take on the role of conflict managers (Barber, 1991) to clearly and assertively discuss those factors which are negotiable and non-negotiable. Within such a relationship, underpinned by empowerment and openness on the issues, it may be easier for social workers to exercise respectful uncertainty (Laming, 2003) when faced with challenging service user accounts and untruths.

The competing and challenging agendas faced by both child protection and mental health social workers is also important to recognise in this debate. Monds-Watson, Manktelow and McColgan (2010) highlight and support the view that there is an inadequate focus on the needs of children in families where there are also parental mental health concerns. These authors caricature this sense of neglect by describing these families in the context of a 'hidden population (p. 38). An additional challenge relates to the skills which professionals need in terms of effectively responding: "While adult mental health professionals may feel they lack expertise in talking to children, children's professionals may feel they do so in mental health, thus rendering both reluctant to deal with this group of children" (Cooklin and Barnes, 2004 in Slack and Webber, 2008, p. 72).

On this point, it is nonetheless significant to note in the Baby $\mathrm{P}$ case, that Tracey Connelly (Baby P's mother), who was being treated for depression, revealed to her mental health worker that she had a male friend in her home (Jones, 2014:16), critical information that otherwise would not have been available to the child protection case conference.SCIE's (2009) Think child, think parent, think family publication is also significant in its summary of the challenges characterising current practice in the interface around screening, assessment, care planning, care provision and review. In regard to screening, problems can be evidenced by social workers 
lacking enquiry skills in asking appropriate questions. Additionally, problems occur in social workers not being aware of the functions of other professionals around mental health and child protection. The fear, mistrust and suspicion with which social workers are sometimes viewed can also act as inhibitors as well as the negative perceptions accompanying mental illness diagnosis itself. There are also issues around parents fearing the loss of parental responsibility and children having fears about separation from their parents. Research conducted by Stanley et al. (2003) revealed worrying degrees of mistrust among mothers with mental health problems towards their child protection social workers: "the relationship with this service was most often characterised as one in which trust was absent, communication was poor" (p. 216). This lack of trust was fundamentally linked with the fear of their children being removed into care. As a result, important information was withheld by mothers, resulting in both inadequate assessments and a lack of support services. The stigma associated with mental health could also act as an obstacle in a parent's willingness to share information (Sartorious 2007). Linked to these issues, the SCIE (2009) study also noted that limited knowledge around mental health problems could also impede child protection social workers from appreciating their impact on parenting when conducting assessments. Stanley et al. (2003) suggested dyadic key worker roles in mental health and child care as a solution where: "each professional could offer an insight into the procedures, legal provisions and interventions specific to their service" (p. 217).

In the context of planning, whilst closer collaborative working may help professionals in untangling multi-faceted familial problems, the difficulties in the perception and interpretation of such problems at the individual level of the professional should not be understated (SCIE, 2009). With a focus on the needs of the parent, the mental 
health professional may, for example, struggle to recognise the inherent and underlying risks of harm to the child whilst the child protection social worker may question any possibility of positive change on the part of the parent. Some commentators also suggest that a tendency towards 'risk-focused and risk aversive intervention is now an ingrained feature of practice with children and families (Frost and Parton, 2009). Munro (2010, p.1139), reports that professional judgments are suffering at the behest of a system which is over occupied with procedural, managerial and tick-box type assessments. Lord Laming (2009) added further weight to this viewpoint in observing that: "there has been a shift towards the "child protection' orientation, particularly in the wake of the death of 'Baby P'" (cited by Hothersall and Maas-Lowit, 2010, p. 74). Jones' (2014) book, chronicling 'The Story of Baby P', uses the term 'Baby P effect' to articulate the current problematic complexion of the child protection landscape. He characterised this as increased child protection caseloads, a tendency towards risk aversion in working with families, increases in applications to the courts and difficulties in both recruiting and retaining social workers in child protection social work. Within such a context, a more family orientated approach to intervention is difficult to envision. Parton (2014:69) described the Baby P case as "a watershed in the politics of child protection" in its heralding of a clear shift in focus from family focused practice towards more crisis driven child protection. Against a backdrop of society being perceived as 'broken', following the media and public outrage to the Baby P case, came calls for social workers to be more 'authoritative' in their exercise of child protection functions, which in turn could lead on to more 'aggressive' forms of state intervention in family life (Parton, 2014:88). 
A further challenge to interface working links to the lack of integration between adults' and children's services. The result is a disjointed service failing to address the holistic needs of the family. Nevertheless, SCIE (2009) highlights a willingness among professionals to collaboratively improve their efforts in meeting the needs of the whole family. Aspiring to this will however involve addressing structural and attitudinal barriers preventing professionals collaborating across their respective settings. In practice, such problems may present where mental health and child care practitioners disagree as to whose responsibility it may actually be to provide services. The fact that child protection and mental health professionals operate under different 'specialist' cultures, encompassing different legislation, policy and procedural guidance also has to be recognised and addressed in terms of recommending practice responses to the interface. Stanley et al. (2003), for example, point to problems around confidentiality, which can seriously impede attempts by professionals to communicate across the interface. An added 'threat' to working together stems from the historical dominance of the bio-medical approach to mental health. This approach has tended not to view the patient in their wider parenting context, which, in turn, inhibits any focus on the needs of significant others such as children (Howard 2000; Baistow and Hetherington 2004; Stallard et al. 2004). This has led to mental health practice which sometimes failed to even identify or record the existence of children (Creswell and Brereton, 2000; Howard 2000).

Recent research by Rouf et al. (2010) does however suggest that more positive outcomes in interface working can be achieved when good quality relationships are forged between professionals in mental health and child protection. They also found that the challenges involved in risk assessment were easier to manage when more collaborative, partnership based relationships were forged with service users. 
Nonetheless, this study does also conclude that the mental health/child protection interface presents complex and professionally demanding challenges around decision making which can be compounded by 'system' problems around communication and, in some instances, professional uncertainty about one's role in judging parenting capacity. Rouf et al. (2010) express dismay that poor interdisciplinary working, such a common theme in child abuse enquiries, was still a problematic aspect hampering effective decision making in their study. Webber, McCree and Angeli's (2013) recent work found that inter-agency joint protocols were particularly useful in helping social workers respond in adult mental health and child care cases. Interestingly they also support Rouf et al's. (2010) finding about the importance of positive interpersonal contact among practitioners involved in such work. Parton (2014) however points out that this is not new: "communication and the sharing of information between professionals has been one of the central messages and practice priorities in relation to child protection work in England since the early 1970's" (p.187). The macro legal and policy contexts around information sharing also need to be considered. The latter point is particularly underscored by Preston-Shoot and Pratt (2014) in their observation that the Data Protection Act 1998 can impede the sharing of information when Local Safeguarding Children Boards are auditing policies and practices in safeguarding which by necessity requires inputs from other sectors and services.

The way in which social workers have responded in other instances where the needs of parents and children often compete can also inform intervention in the mental health/ child protection interface. Domestic violence and child protection is one such example. Devaney (2009) argues that it took considerable time for policy makers to recognise that the needs of victims of domestic violence and children had to be 
jointly addressed. Stanley (1997) suggested that social workers dealing with domestic violence and child protection needed to overcome theoretical differences in approach to work effectively together. 


\section{Case study - applying the recovery approach to the interface}

The following fictitious case vignette is just one example of the types of issues which could potentially face child protection and mental health workers at the interface. The focus is on the social work response in this case but the issues are multi-disciplinary.

Fictitious case study
Marie (36) is a single parent with two children, Jamie (aged 14) and
Clare (aged 9). Marie's relationship with her husband, Clive, ended two
years ago after she found out that he was having an affair. Clive
continues to see the children regularly and Marie continues to live in the
marital home in the outskirts of the city. Marie has been suffering from
depression, anxiety and ruminations for the past ten years and mental
health services are involved. Marie has attempted suicide on two
occasions in the past four years and following these incidents has been
admitted to a mental health in-patient unit. Marie has a very good
friend, Patricia, who was able to look after the children during these
times. Patricia has become concerned about Marie, who told her
the is not here, the children will be taken into care by social workers.
recently that she was hearing voices which were telling her to "end it all
and take the children with her". Marie doesn't think she is going to get
hetter and that mental health services won't help her. She also fears if
she the mental health social worker.


A central challenge is the extent to which the worker can make sufficient time to engage with Marie and all involved in supporting her and her family. As Darlington, Feeney \& Rixon (2005) have highlighted, obstacles to effective interface working may relate to organisational issues such as time, communication and differing systems and/or to the specific nature of the mental health problems and child protection concerns.

In this case, Marie appears to be depressed, potentially presenting a risk of suicide and homicide, and, perhaps crucially, reluctant to engage with mental health services and afraid of involvement by child care social workers. Marie may be thinking extremely negative thoughts about herself, others and the future. The recovery approach suggests that if initial attempts to engage Marie were to lead with and focus exclusively on the risks, this may undermine the development of a trusting relationship with her and her family which is needed to enable a more comprehensive assessment of the possible risks. It is suggested therefore, that in order to achieve meaningful engagement, it is more effective to work with Marie in a way that communicates hope and acknowledges the strengths and resilience in her and her family. This is not to say that the risks do not need to be assessed but that the recovery approach is potentially a more constructive way of achieving this. The social worker should therefore, as a first step, ensure they have sufficient time to explore with Marie her existing strengths and available supports, and her hopes for the future.

Building on Stanley et al.'s (2003) suggested dyadic key worker roles, a triadic approach to Marie's recovery journey will help incorporate the views of Marie, her family members and those involved in offering support and intervention. This will also 
encourage all involved to view Marie and her family's experiences as unique and not defined by any assumptions based on diagnosis. The recovery approach also offers some more structured interventions for working positively with people with mental health problems and so facilitating the process of engagement. One tool is the Wellness Recovery Action Plan (WRAP) (Cook et al. 2011) which could be developed with Marie to enable her to: learn and use strategies that keep her well; identify and respond to symptoms and the early warning signs of crises; and also manage crises when they do occur.

The recovery approach emphasizes the central importance of family and friends. As a second step, in supporting and engaging with the family, it is therefore important that information is exchanged between all of the significant individuals in Marie's life as well as other practitioners. Partnership, as a central social work value, underpins both child protection legislation and the recovery approach. The practitioner, therefore, in individual work with Marie, should explore her understanding of the impact that these experiences and her thoughts could have on her family. This will call for the relationship based approach referred to in the interface literature (Stanley et al. 2003). The fact that Marie has disclosed the content of the voices she is hearing to Patricia suggests that she is concerned and focused on protecting her children.

The social worker's approach is important in affirming and emphasizing Marie's role in managing her own mental health and helping her gain more of a sense of control. An effective action plan should be developed which involves the people that Marie feels are important to her. This builds on established approaches in social work such 
as task-centred practice and systems theory. Within this process, it is important that the social worker includes discussion of the possibility of compulsory intervention in Marie's life from both child protection and mental health perspectives. This fits within Ferguson's (2005) negotiated casework and importantly underscores the need for the social worker to demonstrate leadership and confidence.

Although the focus in this case study has been on the individual family level, the organisational context will also be an important factor in determining whether it is possible for the social workers involved to intervene in this way. The Sainsbury Centre for Mental Health (2009) has specified key organisational challenges for implementing recovery which could be applied across mental health and child protection services. These include: developing relevant service user-led education and training; implementing a range of strategies to enable staff to approach interactions in a recovery informed way; and increasing opportunities for people to build their lives 'beyond illness'. The recovery approach to working with Marie would therefore require the mental health and child care workers involved to be considering issues beyond symptoms, risk and deficits and so be also looking at aspects of Marie's life, resources and hopes that perhaps would currently be neglected. In practice this also means that the social worker has a responsibility to ensure there is a collective organizational commitment to implementing such recovery based ways of working. 


\section{Implications of the recovery approach for training and education}

Arguing for a new approach to addressing these issues and challenges at this interface will inevitably require the need to ensure that students and the qualified workforce are appropriately supported and trained to lead and influence practice at this important juncture. The existing overly regulated and proceduralised complexion of child and family social work, as recognised by Munro (2011), cannot be ignored in this debate. On this point, McLaughlin (2012) argues that: "Effective interprofessional working needs managers who are willing to be less risk averse, controlling and bureaucratically driven to facilitate and encourage the development of professional wisdom, creativity and expertise in the delivery of human services" (2012, p. 6). In addition to evidencing such leadership qualities, Mc Laughlin also reinforces the need to maintain the service user perspective at the centre of any education initiatives aimed at enhancing inter-professional working. Research is increasingly showing that service user involvement in professional education has a significant contribution to make to students' developing knowledge and insights (Author, 2010; Atkinson and Williams, 2011; Skilton, 2011). The participation of service users, currently living with mental health difficulties as parents, could present important opportunities for students to learn about the application of this proposed recovery approach in practice. 


\section{Conclusion}

Central to applying the recovery approach to the mental health/child protection interface is the promotion of user involvement, partnership working and a commitment to strengths and resilience based thinking. This paper has argued that the recovery approach can positively blend with existing preventative ways of working with families aimed at helping to better build capacity and to support families. With engagement as an underpinning ethos it may also be the most effective method of assessing and managing risk, more effective than more confrontational approaches. There is an on-going false dichotomy between family support and child protection, the latter very much coming to the fore when things go wrong (Parton, 2011). The recovery approach, as a form of family support and engagement, may therefore offer a more effective means of protecting children, through its inherent focus on a whole family perspective, where risk is assessed and managed in a spirit of collaboration, empowerment, partnership and openness. Nevertheless, this approach cannot lose sight of the focus on the child's welfare as paramount. Instead, it is argued that the application of recovery principles can work to advance the child's welfare through concentrating on openly helping the parent cope better with aspects of their mental health which are impeding them meeting their children's welfare needs. Balance is an essential ingredient to the success of this approach; balancing the needs of parents with those of children, without compromising the paramountcy principle and without unrealistic optimism about the parent's mental health. It is here, however, where good interagency working will help guide workers in mental health and child protection towards better informed and safer decision-making. In conclusion we propose that a 'family recovery approach' 
should be considered and tested as an integrating framework for practice at this complex interface to promote more effective intervention for the families involved. 


\section{References}

Author. (2010).

Author. (2012).

Anthony, W.A. (1993). Recovery from mental illness: the guiding vision of the mental health service system in the 1990s. Psychosocial Rehabilitation Journal, 16, 11-23.

Atkinson, S. \& Williams, P. (2011). The Involvement of Service Users in Nursing Students' Education. Learning Disability Practice, 14(3), 18-21.

Australian Government (2003). Australian Health Ministers National Mental Health Plan 2003 - 2008. Canberra: Australian Government.

Baistow, K. \& Hetherington, R. (2004). Overcoming obstacles to interagency support: learning from Europe, In Gopfert M, Webster J and Seeman M. (eds.) Parental Psychiatric Disorder: Distressed Parents and Their Families, pp. 361-374. Cambridge: Cambridge University Press.

Barber,J. (1991). Beyond Casework. Basingstoke: Macmillan.

Beresford, P. (2005). “Service user": Regressive or liberatory terminology?' Disability \& Society, 20(4), pp. 469-77. 
Bennett, D. (1978). Social forms of psychiatric treatment, in Wing JK (ed.)

Schizophrenia: Towards a new Synthesis. London: Academic Press.

Boardman, J., \& Roberts, G. (2014). Risk, Safety and Recovery. London: Centre for Mental Health.

Borg, M. \& Kristiansen, K. (2004). Recovery-oriented professionals: Helping relationships in mental health services. Journal of Mental Health, 13, 493-505.

Brandon, M., Bailey, S., Belderson, P., Sidebottom, P., Dodsworth, J., Warren, C. \& Black J. (2009). Understanding Serious Case Reviews and their Impact: A Biennial Analysis of Serious Case Reviews 2005-7. London: Department for Children, Schools and Families.

Brandon, M. (2009). Child fatality or serious injury through maltreatment: making sense of outcomes. Children and Youth Services Review, 31, 1107-1112.

Brandon, M., Bailey, S. \& Belderson, P. (2010). Building on the learning from serious case reviews: a two-year analysis of child protection database notifications 20072009:research brief. London: Department for Education.

Care Services Improvement Partnership, Royal College of Psychiatrists and Social Care Institute of Excellence (2007). A common purpose: Recovery in future mental health services. London: Social Care Institute for Excellence. 
Cleaver, H., Unell, I. \& Aldgate, J. (2010). Children's Needs-Parenting Capacity: The impact of parental mental illness, learning disability, problem alcohol and drug use, and domestic violence on children's development, Second Edition. London: The Stationery Office.

Cook, J.A., Copeland, M.E., Jonikas, J.A., Hamilton, M.M., Razzano, L.A., Grey, D.D. \& Boyd, S. (2011). Results of a Randomized Controlled Trial of Mental Illness Self-management Using Wellness Recovery Action Planning. Schizophrenia Bulletin, Advance Access published March 14, 2011, http:// doi.org/:10.1093/schbul/sbr012.

Cooklin, A. \& Barnes, G.G. (2004). Family therapy when a parent suffers from psychiatric disorder, in: Parental Psychiatric Disorder: Distressed Parents and Their Families (eds. Gopfert M, Webster J, Seeman M), pp. 361-374. Cambridge: Cambridge University Press.

Courtney, M. \& Moulding, T. (2014). Beyond balancing competing needs: embedding involuntary treatment within a recovery approach to mental health social work. Australian Social Work, 67(2), 214-226.

Creswell, C. \& Brereton, J. (2000). Community Mental Health Services and the children of service users. Clinical Psychology Forum, 144, 4-6. 
Darlington, Y., Feeney, J.A. \& Rixon, K. (2005). Practice challenges at the intersection of child protection and mental health. Child and Family Social Work, 10, 239-247.

Davidson, L. (2003). Living outside of mental illness: Qualitative studies of recovery in schizophrenia. New York: New York University Press.

Department of Health. (1995). Child protection: messages from research. London: HMSO.

Department of Health (2009). New Horizons: Towards a shared vision for mental health. London: Department of Health.

Department of Health and Human Services (2003). Achieving the Promise:

Transforming Mental Health Care in America. President's New Freedom

Commission on Mental Health, pub no. SMA-03-3832. Rockville: Department of Health and Human Services.

Devaney, J. (2009). Children's Exposure to Domestic Violence: Holding Men to Account. The Political Quarterly, 80(4), 569-574.

Evans, J. \& Fowler, R. (2008). Family minded: supporting children in families affected by mental illness. Ilford: Barnardo's. 
Falkov, A. (1996). A Study of Working Together Part 8 Reports: Fatal Child Abuse and Parental Psychiatric Disorder. London: Department of Health.

Falkov, A. (1997). Parental psychiatric disorder and child maltreatment, Part I: Context and historical overview. National Children's Bureau Highlight No. 148.

Fardella, J.A. (2008). The Recovery Model: Discourse Ethics and the Retrieval of the Self. Journal of Medical Humanities, 29, 111-126

Ferguson, H (2005) 'Working with Violence, the Emotions and the Psycho-social Dynamics of Child Protection: Reflections on the Victoria Climbie Case'. Social Work Education: The International Journal, Vol 24(7):781-795.

Frost N. \& Parton, N. (2009). Understanding children's social care: Policy, politics and practice. London: Sage.

Glaser, D. \& Prior, V. (1997). Is the term child protection applicable to emotional abuse? Child Abuse Review, 6(5), 315-29.

Harper, D., \& Speed, E. (2012). Uncovering recovery: The resistible rise of recovery and resilience. Studies in Social Justice, 6 (1), 9-25.

Hothersall, S.J, \& Maas-Lowit, M. (2010). Need, Risk and Protection in Social Work Practice. Exeter: Learning Matters. 
Howard, L. (2000). Psychotic disorders and parenting - the relevance of patients' children for general adult psychiatric services. Psychiatric Bulletin, 24, 324-326.

Jacobson, N. \& Greenley, D. (2001). What Is Recovery? A Conceptual Model and Explication. Psychiatric Services, 52(4), 482-485.

Jones, R (2014) The Story of Baby P: Setting The Record Straight. Bristol: Policy Press.

Kearney, P., Levin, E. \& Rosen, G. (2003). Alcohol, drug and mental health problems: working with families. London: Social Care Institute for Excellence.

Laming, H. (2009). The Protection of Children in England: A Progress Report. London: House of Commons.

Laurance, J. (2003). Pure Madness: How Fear Drives the Mental Health System. Abingdon: Routledge.

Martins C \& Gaffan EA. 2000. Effects of early maternal depression on patterns of infant-mother attachment: a meta-analytic investigation. Journal of Child Psychology and Psychiatry 41(6): 737-746. 
McLaughlin, H. (2009). What's in a name: "Client", "Patient", "Customer", "Consumer", "Expert by Experience", "Service User"-What's Next?. British Journal of Social Work, 39(6), 1101-17.

Martins, C. \& Gaffan, E.A. (2000). Effects of early maternal depression on patterns of infant-mother attachment: a meta-analytic investigation. Journal of Child Psychology and Psychiatry, 41(6), 737-746.

Mental Health Commission (1998). Blueprint for mental health services in New Zealand. Wellington: Mental Health Commission.

Mental Health Commission (2005) Annual Report. Including the Report of the Inspector of Mental Health Services 2005. Dublin: Mental Health Commission.

Monds-Watson, A, Manktelow, R and McColgan, M (2010) Social Work with Children when Parents have Mental Health Difficulties: Acknowledging Vulnerability and Maintaining the "Rights of the Child". Child Care in Practice, 16 (1). pp. 35-55.Munro, E. (2010). Learning to Reduce Risk in Child Protection. British Journal of Social Work, 40, 1135-1151.

Munro, E. (2011). The Munro Review of Child Protection: Final Report: A Child Centred System. London: The Stationery Office. 
National Registry of Evidence-based Programs and Practices (2010). Wellness Recovery Action Plan (WRAP). [Online] Accessed on 21.10.12 at http://nrepp.samhsa.gov/ViewIntervention.aspx?id=208.

Office of the Surgeon General (1999). Mental health: a report of the Surgeon General. Rockville: Department of Health and Human Services.

Parton, N. (2011). Child Protection and Safeguarding in England: Changing and Competing Conceptions of Risk and their Implications for Social Work. British Journal of Social Work, 41, 854-875.

Parton, N (2014) The Politics of Child Protection. Basingstoke: Palgrave Macmillan.

Pilgrim, D. (2008). 'Recovery' and current mental health policy'. Chronic IIIness, 4, 295-304.

Preston-Shoot, M \& Pratt M. (2014) Symbolic half-measures? On local safeguarding children boards, their contributions and challenges. In (Ed) Maggie Blyth Moving on from Munro: Improving children's services. Bristol: Policy Press, pp:159 -183.

Reder, P. \& Duncan, S. (1999) Lost Innocents - A Follow-Up Study of Fatal Child Abuse. London: Routledge.

Roberts, G. \& Wolfson, P. (2004) The rediscovery of recovery: open to all. Advances in Psychiatric Treatment, Vol 10, pp. 37-48. 
Roberts, G., Davenport, S., Holloway, F. \& Tattan, T. (Eds.) (2006). Enabling Recovery: The principles and practice of rehabilitation psychiatry. London: Gaskell/Royal College of Psychiatrists.

Rosen, A., \& O'Halloran, P. (2014). Recovery entails bridging the multiple realms of best practice: towards a more integrated approach to evidence-based clinical treatment and psychosocial disability support for mental health recovery. East Asian Archives of Psychiatry, 24(3), 104-109

Rouf, K., Larkin, M. \& Lowe, G. (2011). Making Decisions about Parental Mental Health: An Exploratory Study of Community Mental Health Team Staff. Child Abuse Review , 21, 173-189.

Ruch, G., Turney, D. \& Ward, A. (2010). Relationship-Based Social Work: Getting to the Heart of Practice. London: Jessica Kingsley Publishers.

Rutter, M. (2007). Resilience, Competence and Coping. Child Abuse and Neglect, 31(3), 205-9.

Rutter, M. \& Quinton, D. (1984). Parental psychiatric disorder: effects on children. Psychological Medicine, 14(4), 853-880.

Sainsbury Centre for Mental Health (2009). Implementing Recovery: A new framework for organisational change. London: Sainsbury Centre for Mental Health. 
Saleeby, D. (Ed.). 2006. The Strengths Perspective in Social Work Practice, Fourth Edition. Boston: Allyn and Bacon/Longman.

Sartorius, N. (2007). Stigma and mental health. The Lancet, 370(9590), 810-811.

Scottish Executive (2007). Delivering for Mental Health: The Scottish Recovery Indicator, Report of Conference 30th April 2007. Edinburgh: Scottish Executive.

Scottish Recovery Network (2008). Realising Recovery Learning Materials: Understanding Recovery. Glasgow: Scottish Recovery Network.

Shepherd, G., Boardman, J. \& Slade, M. (2008). Making Recovery a Reality. London: Sainsbury Centre for Mental Health.

Sinclair, R. \& Bullock, R. (2002). Learning from Past Experience - a Review of Serious Case Reviews. London: HMSO.

Skilton, C.J. (2011). Involving Experts by Experience in Assessing Students' Readiness to Practise: The Value of Experiential Learning in Student Reflection and Preparation for Practice. Social Work Education, 30(3), 299-311.

Slack, K. \& Webber, M. (2008). Do we care? Adult mental health professionals' attitudes towards supporting service users' children. Child \& Family Social Work, 13(1), 72-79. 
Slade, M. (2009). 100 ways to support recovery. London: Rethink.

Social Care Institute of Excellence (2009). Think child, think parent, think family: a guide to parental mental health and child welfare. London: SCIE.

Stallard, P., Norman, P., Huline-Dickens, S., Salter, E. \& Cribb, J. (2004). The effects of parental mental illness upon children: a descriptive study of the views of parents and children. Clinical Child Psychology and Psychiatry, 9, 39-52.

Stanley, N. (1997). Domestic violence and child abuse: developing social work practice. Child and Family Social Work , 2, 135-145.

Stanley, N., Penhale, B., Riordan, D., Barbour, R.S. \& Holden, S. (2003). Child Protection and Mental Health Services. Bristol: University of Bristol Press.

Stanley, N., Penhale, B., Riordan, D., Barbour, R.S. \& Holden, S. (2003). Working on the interface: identifying professional responses to families with mental health and child-care needs. Health and Social Care in the Community, 11(3), 208-218.

Trotter, C. (2006). Working with Involuntary Clients - A guide to practice. Londno: Sage. 
Trotter, C. (2004). Helping Abused Children and Their Families. London: Allen \& Unwin/Sage.

Tunnard, J. (2004). Parental Mental Health Problems: Key Messages from Research, Policy and Practice. Dartington: Research in Practice.

Tye, C. \& Precey, G. (1999). Building Bridges: The Interface between Adult Mental Health and Child Protection. Child Abuse Review, 8, 164-171.

Walsh, P. \& Canavan, J. (2014). Strengths-based Practice in Child Welfare, Child Care in Practice, 20(1). Pp. 1-6

Webber, M., McCree, C \& Angeli, P (2013) Inter-agency joint protocols for safeguarding children in social care and adult mental-health agencies: a crosssectional survey of practitioner experiences. Child and Family Social Work. Vol 18(2). pp. 149-158.

Wilson, K., Ruch, G., Lymbery, M. \& Cooper, A. (2009). Social Work: An Introduction to Contemporary Practice. London: Longman. 
